This document is the accepted manuscript version of the following article:

Maabong, K., Machatine, A. G. J., Mwankemwa, B. S., Braun, A., Bora, D. K., Toth, R., \&

Diale, M. (2018). Nanostructured hematite thin films for photoelectrochemical water

splitting. Physica B: Condensed Matter, 535, 67-71.

https://doi.org/10.1016/j.physb.2017.06.054

This manuscript version is made available under the CC-BY-NC-ND 4.0 1icense http://

creativecommons .org/1icenses/by-nc-nd/4.0/

\title{
Nanostructured hematite thin films for photoelectrochemical water splitting
}

Kelebogile Maabong a, b, * Augusto G.J. Machatine a, Benard S. Mwankemwa ${ }^{\text {a,c }}$ Artur Braun ${ }^{\text {d }}$, Debajeet K. Bora ${ }^{\mathrm{d}}$, Rita Toth ${ }^{\mathrm{d}}$, Mmantsae Diale ${ }^{\text {a }}$

${ }^{a}$ Department of Physics, University of Pretoria, Pretoria 0028, South Africa.

${ }^{\mathrm{b}}$ Department of Physics, University of Botswana, UB 0022 Gaborone, Botswana

c Department of Physics, Schools of Physical Sciences, College of Natural and Mathematical Sciences, University of Dodoma, P. Box 338, Dodoma, Tanzania.

${ }^{\mathrm{d}}$ Laboratory of High Ceramics, Empa, Swiss Federal Laboratories for Materials Science and Technology, $\mathrm{CH}-$ 8600 Dübendorf, Switzerland

\begin{abstract}
Nanostructured hematite thin films prepared by dip coating technique were investigated for their photoelectrochemical activity for generation of hydrogen from water splitting. Structural, morphological and optical analyses of the doped/undoped films were performed by X-ray diffraction, high resolution field emission-scanning electron microscopy, UV-vis spectrophotometry and Raman spectroscopy. The photoelectrochemical measurements of the films showed enhanced photoresponse and cathodic shift of the onset potential upon Ti doping indicating improved transfer of photoholes at the semiconductor-electrolyte interface. Films doped with 1 at.\% Ti produced $0.72 \mathrm{~mA} \mathrm{~cm}^{-2}$ at $1.23 \mathrm{~V} v s$ RHE which is 2 times higher than current density for the pure film $(0.30 \mathrm{~mA} \mathrm{~cm}$, at $1.23 \mathrm{~V} \mathrm{vs} \mathrm{RHE).} \mathrm{Gas} \mathrm{chromatography} \mathrm{analysis} \mathrm{of} \mathrm{the} \mathrm{films} \mathrm{also}$ showed enhanced hydrogen evolution at 1 at.\% Ti with respect to pure film.
\end{abstract}

KEYWORDS: Hematite; thin films; dip coating; Ti-doping; photoelectrochemical; gas chromatography.

\section{Introduction}

Photoelectrochemical (PEC) water splitting utilises sunlight energy to drive chemical reactions to produce energy in the form of electrical energy and chemical fuel $[1,2]$. Hematite $\left(\alpha-\mathrm{Fe}_{2} \mathrm{O}_{3}\right)$ is considered an attractive material for PEC water splitting due to its narrow indirect band gap energy $(1.9-2.3 \mathrm{eV})$ which allows photon absorption in the visible region of solar radiation $(400 \leq \lambda \leq 600 \mathrm{~nm})$, and high chemical/electrochemical stability in aqueous environment. Despite its shortcomings such as improper alignment of the conduction band edge to water reduction potential level, short hole diffusion length $(<5 \mathrm{~nm})$, low hole mobility and short excited lifetime (10 ps) $[3,4], \alpha-\mathrm{Fe}_{2} \mathrm{O}_{3}$ continues to attract considerable attention as a promising material for PEC generation of hydrogen, with recent research efforts focused towards understanding of charge transfer kinetics at the semiconductor-electrolyte interface $[3,5,6]$. A number of strategies have been adopted to suppress recombination and 
improve oxygen evolution kinetics at the surface. These include utilization of ultrathin electrodes, nanostructuring, doping, surface modifications and incorporation of thin under layers (electron collectors)[5-8].

Structural and optical properties of the photoelectrode play important role in the PEC performance of the electrode in a PEC cell. A preparation technique-dependence trend of these properties has been reported in literature for hematite [9]. Sol gel methods do not generally yield the high degree of texturing that is required for higher water oxidation activity as compared to complex and expensive vacuum and gas-based techniques. However, the low production cost make these techniques greatly attractive for solar energy conversion applications. They also offers control over preparation conditions such as incorporation of dopant atoms into the host material. Although Ti doping in hematite has been investigated previously, for example by hydrothermal process [10], pulse laser deposition [11], spray pyrolysis [12], successive ionic layer adsorption and reaction SILAR [13] etc, optimization of preparative techniques remain an active area as different optimal doping concentrations are reported for different preparation methods. While the photoelectrochemical properties of hematite nanostructures prepared by dip coating method has been reported $[14,15]$, we are not aware of the similar studies of Ti-doped films. Here we report on nanostructured Tidoped $\alpha-\mathrm{Fe}_{2} \mathrm{O}_{3}$ films prepared dip coating and investigated for their PEC solar water splitting activity. Gas chromatography analysis of the films showed enhanced hydrogen gas evolution when doping with 1 at.\% Ti.

\section{Experimental Details}

\subsection{Synthesis of the photoelectrode}

Hematite thin films were deposited by dip coating of iron oleate sol-gels made using $\mathrm{Fe}\left(\mathrm{NO}_{3}\right)_{3} \bullet 9 \mathrm{H}_{2} \mathrm{O}$ as the iron precursor and a process similar to that previously described [16]. Briefly, prior to deposition the fluorine doped tin-oxide (FTO) substrates were cleaned ultrasonically in acetone, ethanol and deionized water for 10 min each followed by rinsing with ethanol and dried with nitrogen gas. The substrate was immersed into the sol for $30 \mathrm{~s}$ then withdrawn with a speed of $130 \mathrm{~mm} / \mathrm{min}$. The iron-oleate films were dried at $70{ }^{\circ} \mathrm{C}$ on a hot plate before annealed at $550{ }^{\circ} \mathrm{C}$ at a heating rate of $10{ }^{\circ} \mathrm{C} / \mathrm{min}$, for $0.5 \mathrm{~h}$. The deposition, drying and heat treatment steps were repeated in this order, for each layer at a time until thin films with three layers of were obtained. Small amount of titanium (IV) butoxide with 
distilled water were added to the precursor to obtain Ti doping concentrations of $0.5,1$ and 2 at. $\%$.

\subsection{Characterization of the thin films}

The phase composition analysis of the films was determined by powder X-ray diffraction (XRD) (PAN analytical X'Pert, Cu1-K $\mathrm{K}_{\alpha}$ radiation). The surface morphology was carried out using field emission gun scanning electron microscopy (FEG-SEM, Carl Zeiss AG) operating at $2 \mathrm{KV}$. Raman spectra of the films were obtained in $180^{\circ}$ back scattering geometry with a $0.15 \mathrm{~mW} \mathrm{Ar}{ }^{+}$laser at a wavelength of $514.5 \mathrm{~nm}$, focussed on a spot size of about $5 \mu \mathrm{m}$. The UV-Vis spectra of the films were measured with a Cary 5E UV/VIS/NIR spectrophotometry, using a blank FTO substrate as reference. Photoelectrochemical measurements of the hematite film photoelectrodes was carried out using a three-electrode configuration with hematite electrode, a platinum plate counter electrode and saturated $\mathrm{Ag} / \mathrm{AgCl} / \mathrm{saturated} \mathrm{KCl}$ reference electrode in contact with $1 \mathrm{M} \mathrm{KOH} \mathrm{(pH} \mathrm{13.6)} \mathrm{electrolyte,.} \mathrm{The} \mathrm{photocurrent}$ measurements were recorded with a Voltalab potentiostat from -0.3 to $+0.7 \mathrm{~V}$ vs. $\mathrm{Ag} / \mathrm{AgCl}$ swept at a rate of $10 \mathrm{mV} \mathrm{s}^{-1}$ in dark and under simulated light using a xenon lamp (LOT Oriel). All the potentials were converted to the reversible hydrogen electrode (RHE) scale by the equation $V_{R H E}=V_{A g / A g C l}+0.059 p H+V_{A g / A g C l}^{0}[6]$. To monitor the amount of oxygen $\left(\mathrm{O}_{2}\right)$ and hydrogen $\left(\mathrm{H}_{2}\right)$ evolved from the reaction between the $\alpha-\mathrm{Fe}_{2} \mathrm{O}_{3}$ and $\mathrm{H}_{2} \mathrm{O}$ a closed cycle recirculating gas chromatography (GC) system equipped with a custom-built, sealed electrochemical cell developed at Empa was used.

\section{Results and Discussion}

X-ray diffraction (XRD) measurements were carried out to examine the phase purity and crystallinity of the samples. Fig. 1 shows X-ray diffraction spectra of pure and Ti-doped $\alpha$ $\mathrm{Fe}_{2} \mathrm{O}_{3}$ thin films prepared on FTO substrate. The peak intensity distribution corresponds to that of polycrystalline hematite with rhombohedral structure, space group $R \overline{3} c$ (JCPDS \#730603). The prominent peaks observed at $2 \theta$ values of $~ 33.1$ and $35.5^{\circ}$ corresponds to (104) and (110) crystal planes respectively. Additional weaker diffraction peaks at $2 \theta$ values corresponding to (l $\left.\begin{array}{lll}0 & 1 & 2\end{array}\right),\left(\begin{array}{ll}113\end{array}\right),\left(\begin{array}{lll}0 & 2 & 4\end{array}\right)$, and (116) planes were also observed. The XRD patterns are consistent with previous studies [14]. The peaks showed broadening with 
increasing doping concentration suggesting decrease in crystallite size with doping. The average crystallite size was determined from the standard Debye Scherer's equation [17] using the peaks of (104) and (110) planes and obtained values as 37, 35.5, 32 and $30.5 \mathrm{~nm}$ for $0,0.5,1$ and 2 at. $\%$ Ti doped $\alpha-\mathrm{Fe}_{2} \mathrm{O}_{3}$, respectively. The absence of extra peaks corresponding to impurities or other phases confirms the successful preparation of the hematite phase. The strong peaks identified by $(*)$ in Fig. 1 originated from the FTO substrate (cassiterite, phase, [JCPDS 77-0451]).

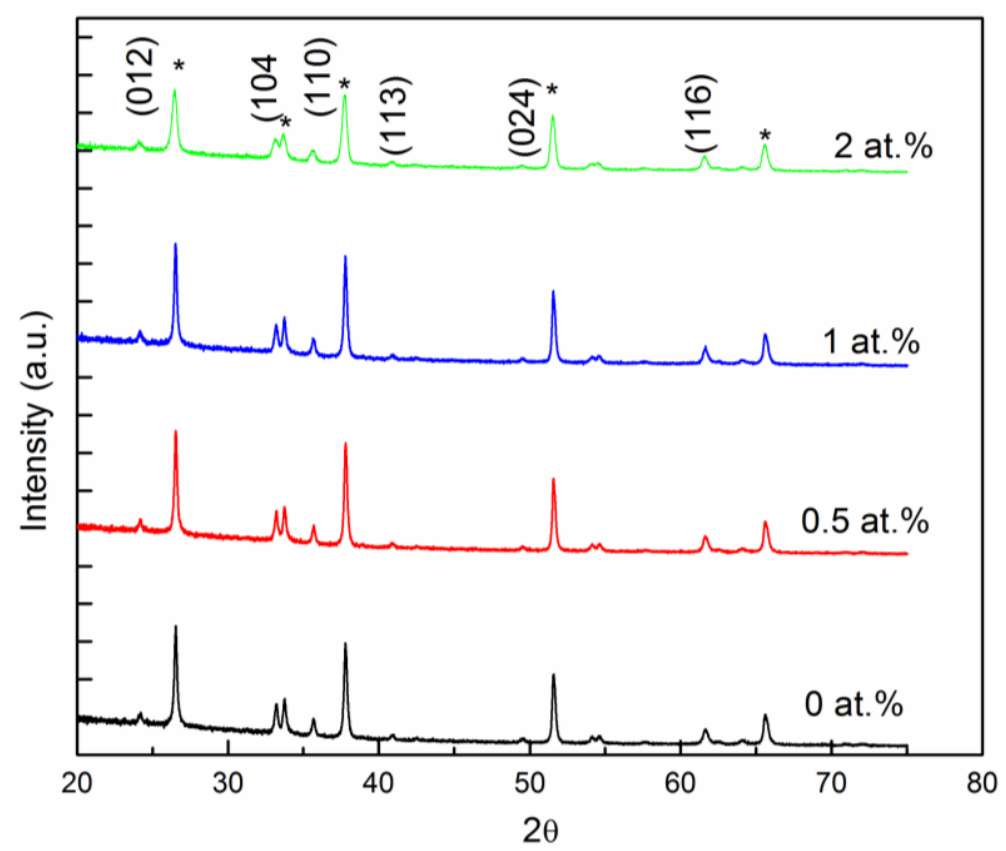

Fig. 1. X-ray diffraction spectra of pure and Ti-doped hematite thin films prepared by dip coating on FTO substrate annealed at $550{ }^{\circ} \mathrm{C}$.

SEM micrographs of the films in Fig. 2 show synthesis of nanoparticles for all the samples. Ti-doped hematite nanostructures show morphology with decreased feature size with relative to the undoped films. Smaller nanoparticles offers increased surface area and minimizes the hole diffusion length. 

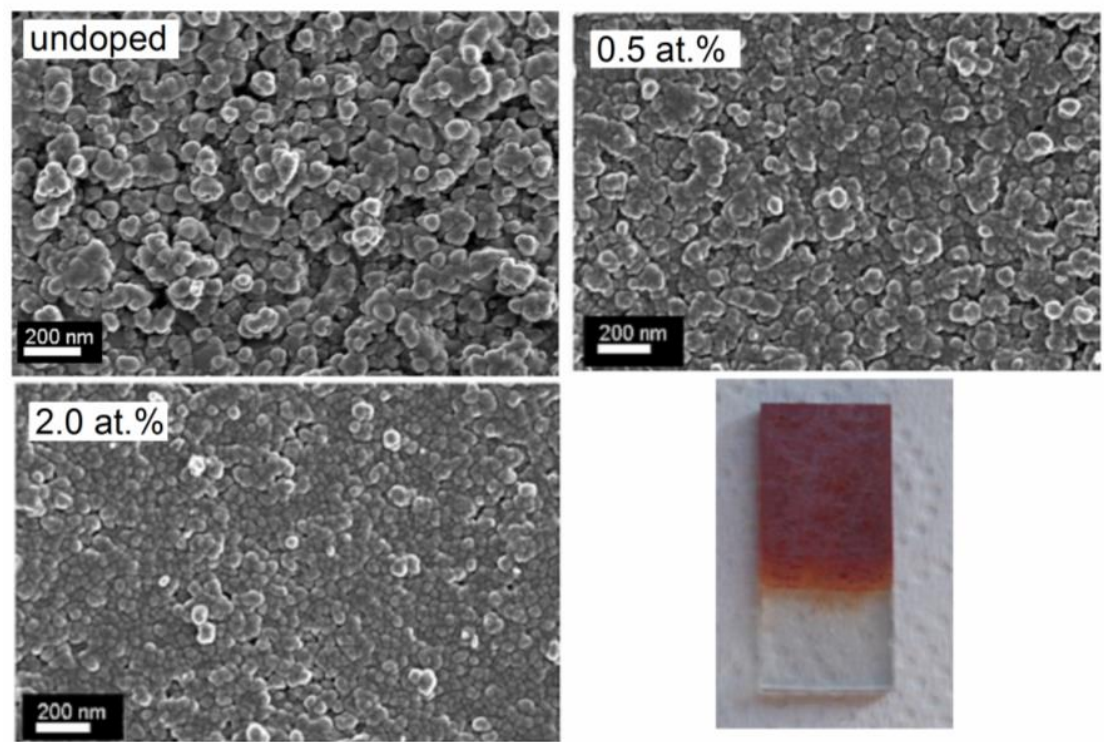

Fig. 2. SEM images of pure and Ti-doped hematite nanostructures sintered at $550{ }^{\circ} \mathrm{C}$. Also included is the photograph of the pure hematite film.

Typical UV-visible absorption spectra of the pure $\alpha-\mathrm{Fe}_{2} \mathrm{O}_{3}$ nanostructures are presented in Fig. 3. According to computational studies of electronic structure of hematite by Huda et al [18], the lowest conduction band and highest valence band in the electronic band structure are not at the same wave-vector in the Brillouin zone, indicating hematite as an indirect gap material. From the UV-vis optical absorption measurement, the optical band gap energy of the semiconductor can be determined from the absorption coefficient according to the Tauc relation [2], for allowed indirect and direct transitions in the material. The energy indirect gap for pure film was obtained as $2.09 \pm 0.05 \mathrm{eV}$. Doping with $\mathrm{Ti}, \mathrm{Si}, \mathrm{Zn}, \mathrm{Cr}, \mathrm{Cu}$ atoms etc, can alter the band edge positions in the electronic band structure that defines the energy gap, altering the electronic properties of the host compound. However, in here no significant change in energy band gap after doping with Ti was observed except for the film doped with 1 at.\% which showed a small shift to $2.08 \pm 0.05 \mathrm{eV}$ (Fig. 3(b)). The optical band gap was also calculated from the position of the maximum of the first derivative of transmittance with respect to wavelength $(\mathrm{dT} / \mathrm{d} \lambda)$ [19], as seen in Fig. 3(c). The results show a cut-off wavelength at $\sim 582$ which corresponds to $2.1 \mathrm{eV}$. 

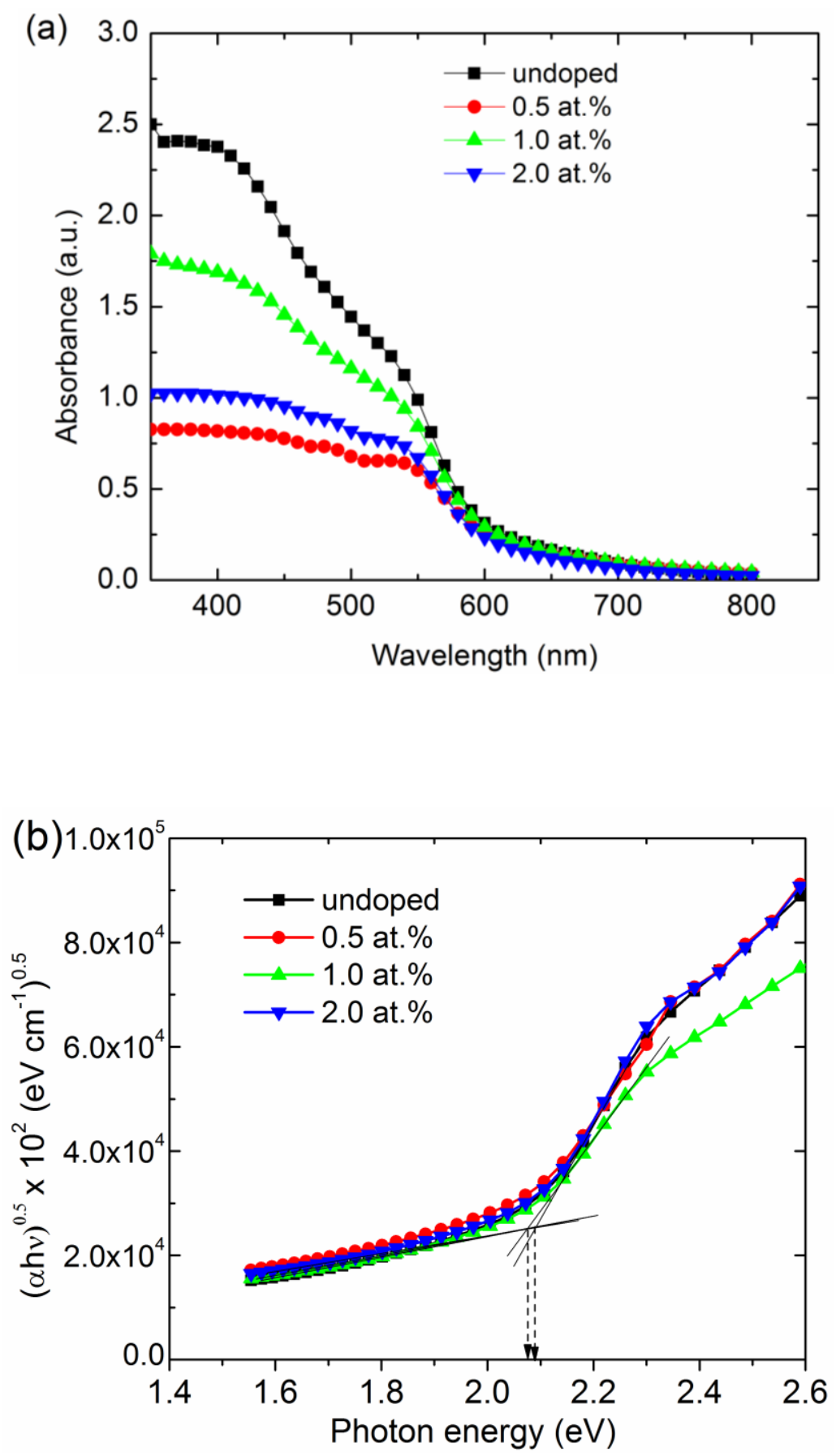


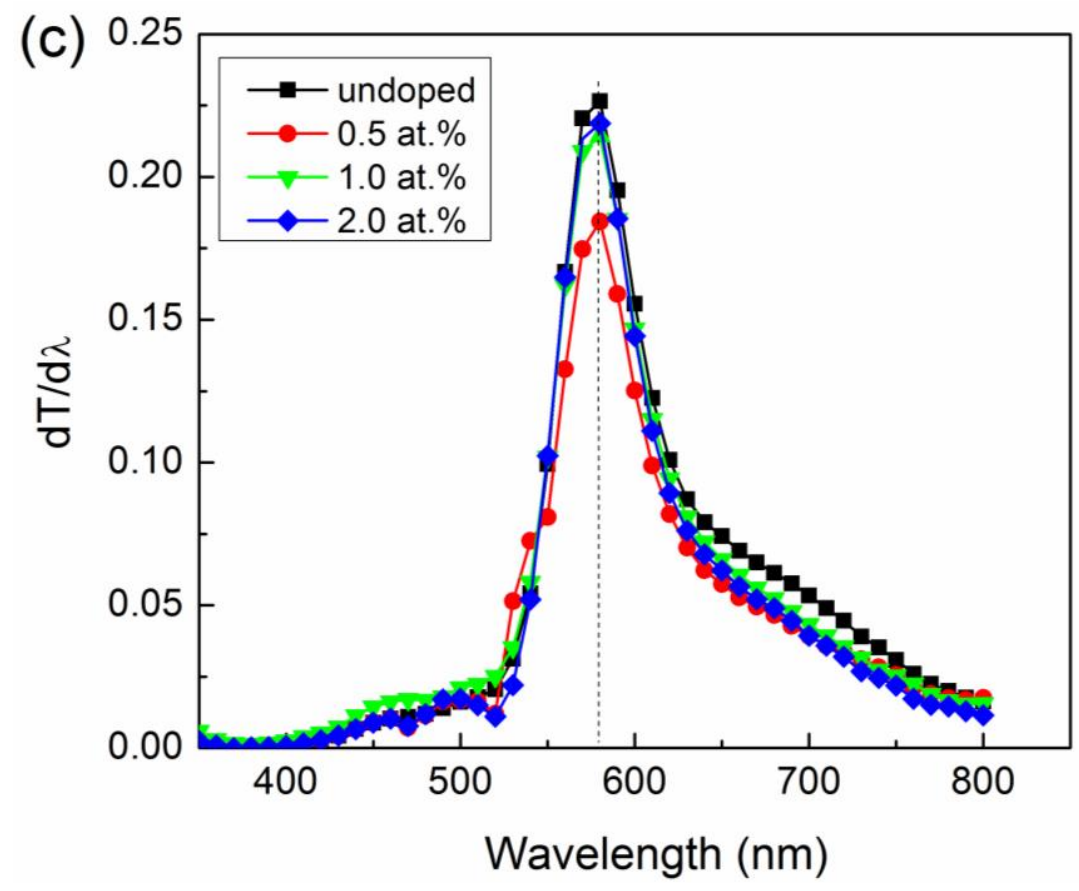

Fig. 3. (a) UV-vis Absorption spectra of pure and Ti doped $\alpha-\mathrm{Fe}_{2} \mathrm{O}_{3}$ nanoparticles. Calculated optical band gap of the nanoparticles from (b) Tauc model and (c) position of the maximum of the first derivative of transmittance with respect to wavelength $(\mathrm{dT} / \mathrm{d} \lambda)$.

Raman theory has been discussed in literature to various degree of sophistication. In here, we take a simple and brief attempt to interpret the first order Raman peaks. $\alpha-\mathrm{Fe}_{2} \mathrm{O}_{3}$ crystallizes into the corundum structure, trigonal space group $R \overline{3} c\left(D_{3 d}^{6}\right)$ with two formula units per primitive unit cell. The lattice is built on a slightly distorted framework of hexagonal closepacked containing $\mathrm{MO}_{6}$ octahedral that share face and three edges with another octahedral [20] The iron and oxygen sites have $C_{3}$ and $C_{2}$ symmetry, respectively. Because of the long wavelength limit, the conservation of momentum allows first-order Raman experiments to show only vibrational structures near or at the center of the Brillouin zone ( $\Gamma$-point), with wave vector $k=0$ [21]. Group theory predicts seven Raman active modes at the zone center; two fully symmetric (non-degenerate) $\mathrm{A}_{1 \mathrm{~g}}$ modes and five doubly degenerate $\mathrm{E}_{\mathrm{g}}$ modes, due to single phonon processes. Fig. 4 shows the micro-Raman spectra of pure and doped $\alpha$ $\mathrm{Fe}_{2} \mathrm{O}_{3}$ nanoparticles. All samples showed the seven predicted Raman modes for $\alpha-\mathrm{Fe}_{2} \mathrm{O}_{3}$. No extra peaks were observed which confirms purity of films. The spectra acquired on doped films showed a slight broadening and shifting of peaks to higher frequencies with doping 
concentration. Raman peaks can shift due to factors like lattice strain and stress as a result of lattice imperfections and local lattice disorder [22].

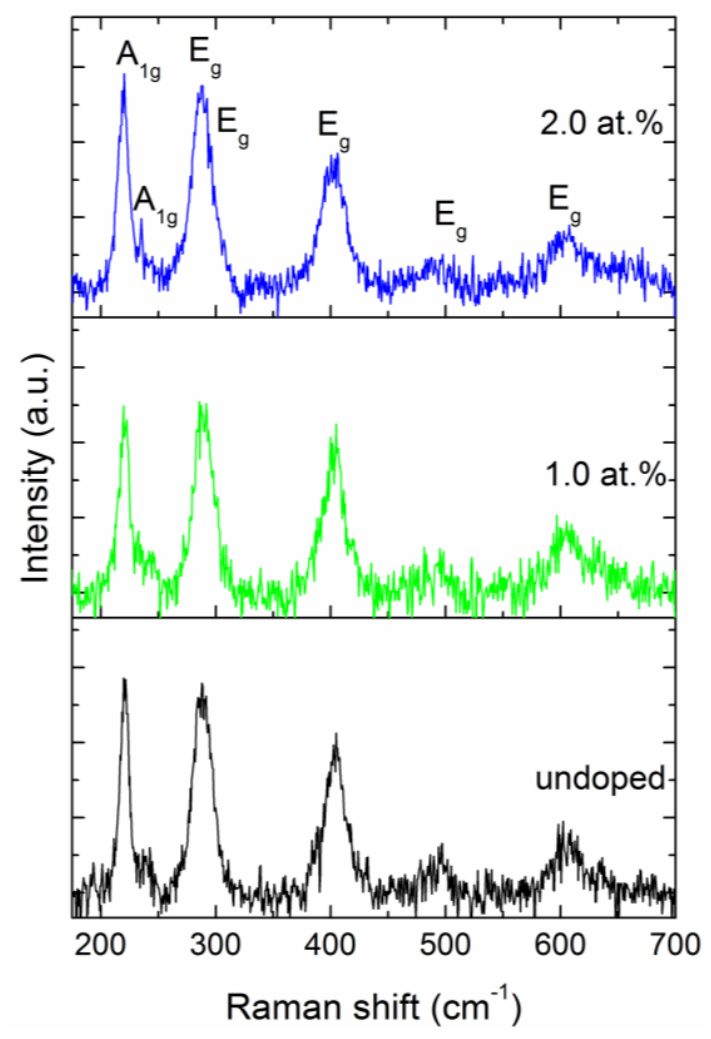

Fig. 4. Raman spectra of hematite nanostructures for pure and doped thin films measured in backscattering geometry.

The films were examined for PEC water splitting under illumination and darkness. In practice thin iron oxide films have been found to exhibit poor PEC performance due to poor oxygen kinetics at the surface and rapid recombination of photogenerated electrons and holes resulting from poor optoelectronic properties of hematite. Fig. 5 shows plots of photocurrent density (a) and squared photocurrent density against the applied potential (b) $\left(\mathrm{J}^{2}-\mathrm{V}\right)$ [23], used to estimate the photocurrent onset potentials for the films. Pure hematite photoelectrode produced current density of $0.30 \mathrm{~mA} / \mathrm{cm}^{2}$ at $1.23 \mathrm{~V} v s$. RHE. Because of the low efficiency of pristine hematite for water photo-oxidation, a small percent of Ti were incorporated into $\alpha$ $\mathrm{Fe}_{2} \mathrm{O}_{3}$ crystal with the intention to improve the bulk properties and their PEC response. Substitution of $\mathrm{Ti}^{4+}$ at $\mathrm{Fe}^{3+}$ ion positions introduces extra donors in the host lattice, increasing donor density. The extra electron converts a neighbouring $\mathrm{Fe}^{3+}$ ion to $\mathrm{Fe}^{2+}$, forming a donor level within the energy gap, increasing the probability of electrons from valence band reaching the conduction band [18]. The positive effect of doping is indicated by enhancement 
in photocurrent density of the films together with a cathodic shift in onset potentials of photocurrent.
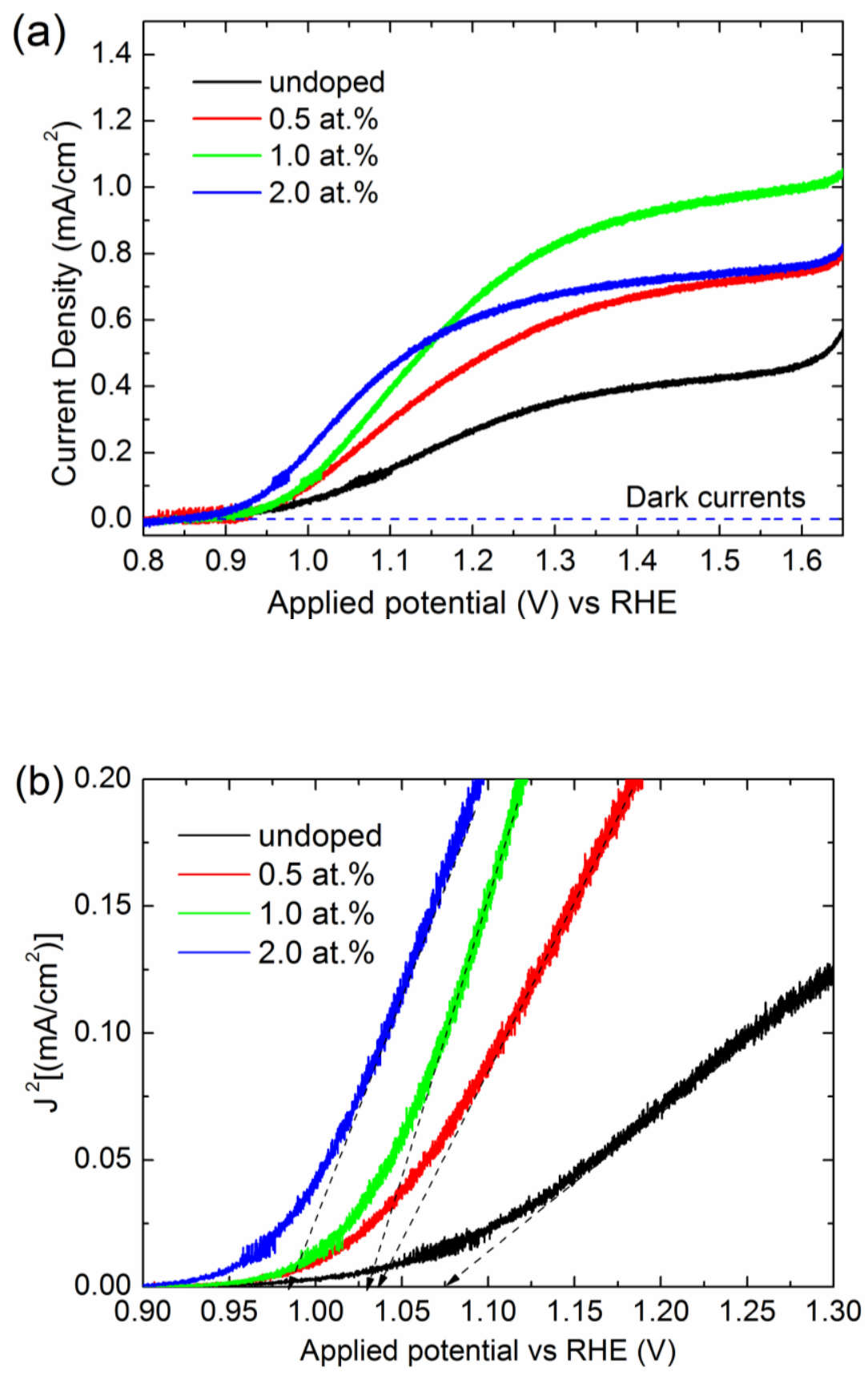

Fig. 5. Photocurrent densities for pure and $\mathrm{Ti}: \alpha-\mathrm{Fe}_{2} \mathrm{O}_{3}$ photoelectrode thin films prepared on FTO substrates in contact with $1 \mathrm{M} \mathrm{KOH}$ (a). The estimated onset potentials for the electrodes is also shown in (b) by the arrows on the dotted lines. 
Ti resulted in an increase in current density to a maximum value of $0.72 \mathrm{~mA} / \mathrm{cm}^{2}$ at 1.23 for film photoanodes doped with 1.0 at.\% Ti. Although it still increased with relative to pure and the 0.5 at.\% Ti doped film $\left(0.52 \mathrm{~mA} / \mathrm{cm}^{2}\right)$ (Fig 5 (a), the current density decreased to $0.64 \mathrm{~mA} / \mathrm{cm}^{2}$ at $1.23 \mathrm{~V}$ vs. RHE at 2 at.\% Ti. The enhancement in photocurrent upon doping may be attributed to improved charge separation as result of increased electron conductivity which leads to improved charge separation of photogenerated holes and electrons. The bulk recombination of holes and electrons was suppressed, resulting in improved charge transfer to the electrolyte. Huda et al [18], presented a comprehensive theoretical study on the effects of 3d transitions metals in hematite using density-functional theory (DFT) and concluded that incorporation of $\mathrm{Ti}$ in $\alpha-\mathrm{Fe}_{2} \mathrm{O}_{3}$ results in reduced effective electrons mass, hence improved electron mobility. At higher concentrations, $\mathrm{Ti}^{4+}$ would have defect scattering/recombination properties and suppresses charge separation efficiency, and this results in lowering the photocurrent [24]. Furthermore, Saroj et al [12], also noted that at higher Ti doping concentrations, above optimal doping concentration, the donor density decreases as excess electrons localises on $\mathrm{Fe}^{3+}$ ions, decreasing electric field within the space charge layer resulting in low field driven charge separation. The plateau current at $1.45 \mathrm{~V} v s$. RHE increased from 0.4 to $0.92 \mathrm{~mA} / \mathrm{cm}^{2}$ for pure and 1 at.\% Ti doped film, respectively (Fig. 5(a)). The value of the plateau current density reflects on the probability of photogenerated holes reaching the semiconductor-electrolyte interface and take part in water oxidation, at such high potentials [25]. The amount of $\mathrm{O}_{2}$ and $\mathrm{H}_{2}$ evolution versus time are presented in Fig. 6. Only the pure and 1 at.\% Ti doped films were examined. As clearly seen the amount of $\mathrm{H}_{2}$ evolved was significantly increased upon doping with 1 at.\%, which renders Ti-doped film prepared by dip coating promising for the PEC technology despite the low current density produced with relative to other methods, eg, hydrothermal by Deng et al [10]. The decrease in $\mathrm{O}_{2}$ evolution upon doping was not well understood at the time of preparation of the manuscript and is still under investigation. The enhancement in $\mathrm{H}_{2}$ evolution was associated with improved charge transfer to the electrolyte as a result Ti doping. 

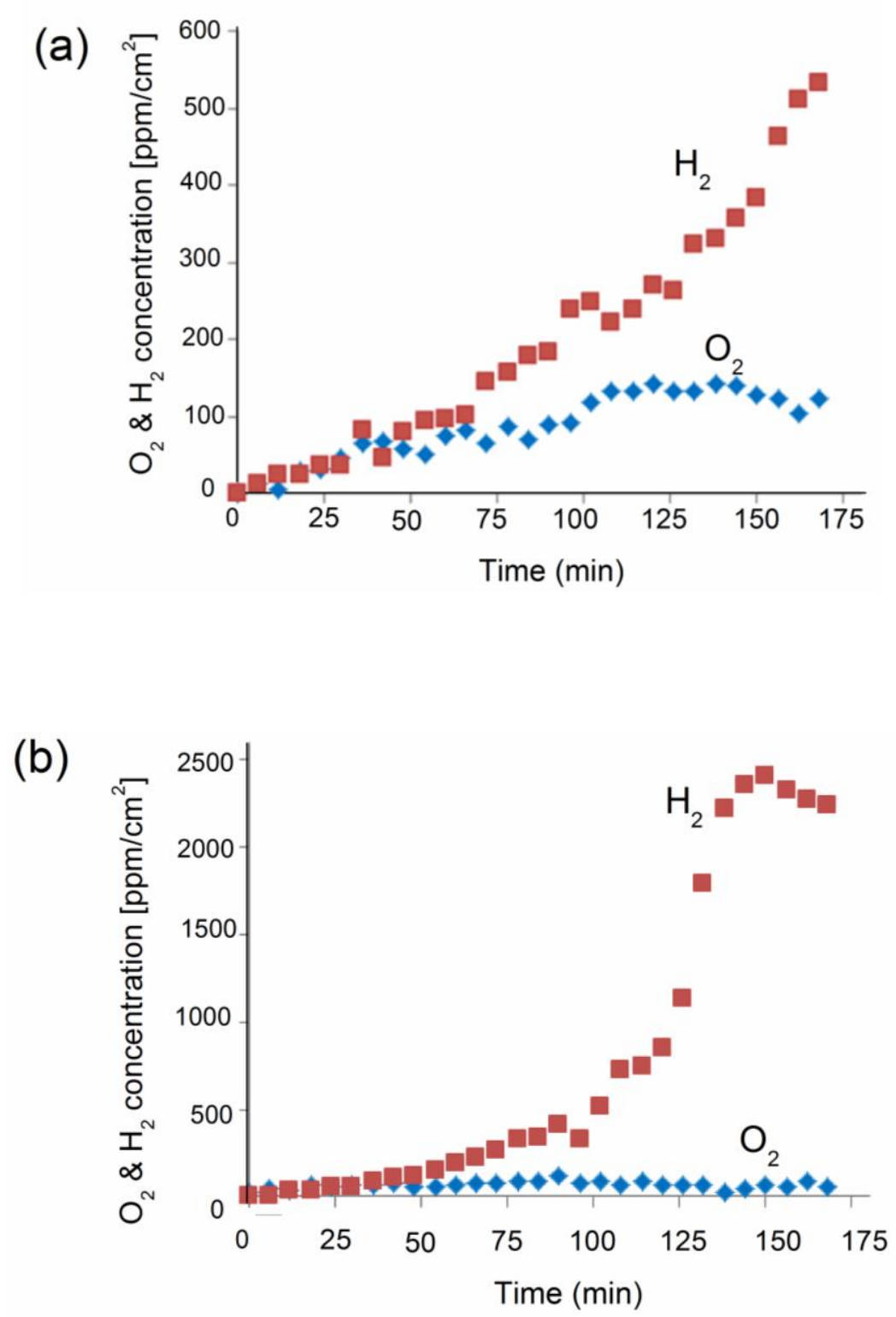

Fig. 6. $\mathrm{O}_{2}$ and $\mathrm{H}_{2}$ evolution versus time at $+1.3 \mathrm{~V}$ vs. $\mathrm{Ag} / \mathrm{AgCl}$ bias for (a) pure and (b) 1 at.\% Ti doped $\alpha-\mathrm{Fe}_{2} \mathrm{O}_{3}$ photoanodes.

\subsection{Conclusion}

Pure and Ti-doped hematite thin films were prepared via simple dip coating method and investigated for their photoelectrochemical properties for generation of hydrogen from water splitting. Ti-doped hematite nanostructures show morphology with decreased feature size with relative to the pure films, which offers increased effective surface area compared to those of pure counterpart nanostructures. The photoelectrochemical analysis of the films showed enhanced photoactivity and cathodic shift in onset potential upon $\mathrm{Ti}$ doping, 
suggestive of improved charge separation therefore enhanced transfer of photogenerated holes to the semiconductor-electrolyte interface. The current density increased from 0.30 $\mathrm{mA} / \mathrm{cm}^{2}$ for pure films to highest value of $0.72 \mathrm{~mA} / \mathrm{cm}^{2}$ at $1.23 \mathrm{~V} v s$. RHE upon doping with 1 at.\% $\mathrm{Ti}$ and slightly more hydrogen was evolved from the same photoelectrode as compared to those of pure counterpart photoelectrodes. Doping with Ti was effective in improving the photoelectrochemical properties of crystalline hematite fabricated via dip coating.

\section{Acknowledgment}

The results of this work was supported by the Swiss-South African Joint Research (SSAJR) Project IZLSZ2149031; the Swizz SNF grant R'Equip 206021-121306 and National Research Foundation of South Africa (NRF). K.M acknowledges University of Botswana for financial support. We would like to acknowledge Mrs. Wiebke in the Department of Geology, University of Pretoria for XRD data.

\section{References}

[1] M. Grätzel, Nature 414(6861) (2001) 338-344.

[2] R. Van de Krol, M. Grätzel, Photoelectrochemical hydrogen production, Springer, New York, 2012.

[3] M. Barroso, S.R. Pendlebury, A.J. Cowan, J.R. Durrant, Chem. Sci. 4(7) (2013) 2724-2734.

[4] J.Z. Zhang, MRS Bulletin 336 (2011) 48-55.

[5] O. Zandi, T.W. Hamann, The journal of physical chemistry letters 5(9) (2014) 1522-1526.

[6] O. Zandi, A.R. Schon, H. Hajibabaei, T.W. Hamann, Chem. Mater. 28 (2015) 765-771.

[7] X.Y. Meng, G.W. Qin, S. Li, X.H. Wen, Y.P. Ren, W.L. Pei, L. Zuo, Applied Physics Letters 98(11) (2011) 112104.

[8] J.Y. Kim, G. Magesh, D.H. Youn, J.-W. Jang, J. Kubota, K. Domen, J.S. Lee, Single-crystalline, wormlike hematite photoanodes for efficient solar water splitting, 2013, pp. 1-8.

[9] A.G. Tamirat, J. Rick, A.A. Dubale, W.-N. Su, B.-J. Hwang, Nanoscale Horiz. 1(4) (2016) 243-267.

[10] J. Deng, J. Zhong, A. Pu, D. Zhang, M. Li, X. Sun, S.-T. Lee, J. Appl. Phys. 112(8) (2012) 084312.

[11] T.S. Atabaev, N.H. Hong, Y.-H. Hwang, M. Ajmal, H.-K. Kim, Appl. Phys. A 118 (2015) 1539-1542.

[12] S. Kumari, A.P. Singh, Sonal, D. Deva, R. Shrivastav, S. Dass, V.R. Satsangi, Int. J. Hydrogen Energy 35(9) (2010) 3985-3990.

[13] A.J. Abel, A.M. Patel, S.Y. Smolin, B. Opasanont, J.B. Baxter, J. Mater. Chem. A 4(17) (2016) 6495-6504.

[14] D.K. Bora, A. Braun, E.C. Constable, Energy Environ. Sci. 6(2) (2013) 407-425.

[15] Y. Hu, D.K. Bora, F. Boudoire, F. Haeussler, M. Graetzel, E.C. Constable, A. Braun, Journal Of Renewable And Sustainable Energy 5(4) (2013).

[16] K. Maabong, Y. Hu, A. Braun, A.G.J. Machatine, M. Diale, J. Mater. Res. 31(11) (2016) 1580-1587. [17] V.D. Mote, Y. Purushotham, B.N. Dole, Journal of Theoretical and Applied Physics 6(6) (2012) 18.

[18] M.N. Huda, A. Walsh, Y. Yan, S.-H. Wei, M.M. Al-Jassim, J. Appl. Phys. 107(12) (2010) 123712.

[19] C. Moditswe, C.M. Muiva, A. Juma, Optik 127(20) (2016) 8317-8325.

[20] R.L. Kurtz, V.E. Henrich, Phys. Rev. B. 25(6) (1982) 3563-3571. 
[21] P.Y. Yu, M. Cardona, Fundamentals of Semiconductors-Physics and Materials Properties, Springer, London New York, 2010.

[22] E. Smith, G. Dent, Modern Raman spectroscopy-A practical approach, John Wiley \& Sons Ltd, England, 2005.

[23] J. Cao, T. Kako, N. Kikugawa, J. Ye, J. Phys. D: Appl. Phys. 43(32) (2010) 325101.

[24] T.S. Atabaev, M. Ajmal, N.H. Hong, H.-K. Kim, Y.-H. Hwang, Applied Physics A 118(4) (2014) 1539-1542.

[25] S.D. Tilley, M. Cornuz, K. Sivula, M. Gratzel, Angew. Chem. Int. Ed. 49(36) (2010) 6405-6408. 